Europe's Journal of Psychology, 7(4), pp. 640-663

www.ejop.org

\title{
From icon to person: Findings from a qualitative study of motherhood in Crete
}

\author{
Sofia Triliva \\ Department of Psychology, University of Crete
}

Catherine M. Brusten

PhD. Patriarchou Grigoriou 11

\begin{abstract}
An exploratory study sought to reconcile certain contradictions regarding the role of mothers as presented in the social science literature through probing subjective accounts of mothers in the rapidly changing social milieu of Greece. Previous research that has focused on motherhood in Greek society has highlighted how women who become mothers have been given iconic status. However, modern Cretan mothers are increasingly faced with novel challenges. The subjective perceptions of motherhood of Cretan women attending a community group which focused on parenting were probed. Qualitative analysis was carried out on the written narrative accounts. Participants' responses corresponded to the following levels of narrative analysis: personal, interpersonal/transgenerational, and societal-ideological. Narratives revealed that mothers were experiencing high levels of personal and interpersonal dissonance which impinged upon their identities and challenged them in their roles as mothers. The women's narrative accounts underscored the emotional and social importance of having achieved the coveted role of being a mother, the stressful and pressure inducing social context which mandates how the mothering role should be enacted, and dialectics between the personal, intergenerational and social levels of experience. The implications of these findings are discussed with regard to identity and relatedness within the family and how social and professional constructs of mothering lag behind social changes.
\end{abstract}

Keywords: motherhood, Crete, subjective accounts, qualitative research. 


\section{Motherhood in Greece}

Throughout history the icon of the mother has had a very special place in Greek culture. This icon has been shrouded with an almost mystical existence that has positioned mothers as social objects of great respect - respect even to the point of pious devotion. As Paxson (2004) remarks: 'Motherhood in Greece, with its iconic representation in the Panayia, or All Holy Mary, Mother of God, is an indisputable, absolute good. Motherhood is an idiom of morality, and such idioms, as Michael Herzfeld notes, benefit from "the semiotic illusion of invariance" (Paxson, 2004, p. 14). Given the special place that the mother occupies in Greek society, it is not surprising that through the years there have been several studies carried out by social scientists on the perceptions of motherhood. In this introduction, we begin by reviewing some of the pivotal scholarly work on mothering and motherhood in Greece.

Vassiliou (1966) conducted a study on family values and parenting using what he described as a large representative sample of Athenians (unfortunately, exact numbers of participants were not given in his work). He asked participants to supply descriptors to the word "mother". In analyzing these answers, Vassiliou (1966) concluded that motherhood was constructed as a wholly positive experience, with $29 \%$ of the participants going so far as to using expressions such as: 'The Virgin Mary', 'Goddess', 'A sacred figure', and 'The gold blanket that covers and protects us'. The religious-like sense of devotion and awe associated with motherhood was captured in this early study. Vassiliou \& Vassiliou (1970) summarized their findings as follows:

\footnotetext{
"Mothers are assigned and assume a primary role concerning child-rearing. It is not simply a matter of being assigned this role. They seem to seek it out, and compete with other potential sources of child rearing (fathers, grand-parents, other relatives, teachers, etc.) in order to perform it exclusively. This is quite consistent with the fact that "Mother" represents the only totally respectable female social role. Outside motherhood, the woman has a negative stereotype, no significant social role and, if married, her role involves mainly "house activities". But once a mother the woman she becomes holy. Almost unconditional love and respect are due to her. Naturally then "mothering" for her, becomes as all important and inclusive as life itself" (p. 443).
}

The second major study on mothering in Greece reported in the literature is work published by Doumanis in the 1980s. Greek society changed greatly between the early Vassiliou (1966) study and the Doumanis (1983) publications. Doumanis, in an attempt to capture the changing cultural milieu, compared Greek mothers living in 
the villages of Ipeiros and in Athens. Doumanis' research, which spanned approximately 10 years and was completed in three different phases, presents snapshots of two different worlds, that of the village and that of the more 'modern' world of the Athens metropolitan area. Domanis (1983) concluded that mothers in the traditional social milieu, who lived within a network of mutual support and interdependence, functioned in an unconstrained and unhurried manner in their role. In contrast to women living in an urban environment, the women who were embedded in the traditional milieu were not ridden with ambivalence, uncertainties and intrapersonal conflict. On the other hand, the women who lived and raised their children in the Athens metropolitan area strived to prepare their children for a social environment that they themselves had not fully understood, adopted or reflected upon meaningfully. Doumanis (1983) surmises that it was inevitable for Athenian mothers to feel anxious to the core in their effort to reconcile their own and their children's needs.

Several years after Doumanis' (1983) study, Dragona (1987) published a study on Greek women's attitudes toward pregnancy, labor, and motherhood. She found that these new mothers often reported an acute sense of responsibility coupled with uncertainty about what to do and how. Feelings of anger apparently surfaced when mothers had to cope with the baby's persistent crying and their own chronic fatigue and vulnerability. She found that a baby's crying seems to create feelings of guilt and inadequacy, with mothers believing that they cannot cope adequately with their maternal role. Dragona (1987) concluded that these mothers have few chances to confirm that they are 'good' mothers and that their exposure to much contradictory information from experts and other sources adds to their ambivalence and anxiety.

A decade later, Katakis (1998) published an influential book on the Greek family and its relational evolution through the years. She categorized the Greek family as having three forms of identity: the traditional identity, the nuclear identity, and the modern identity. Within the framework of the traditional family, it was the destiny of both men and women to become parents. As parents, they had to sacrifice their personal needs and desires for the 'good' of family cohesion and more importantly for the children. In the nuclear family, children were the center of family life and parents had to equip their children with the necessary provisions to become 'useful' social beings, for the honor of their family, their nation, and their religion. The means to achieve this was through education. Finally, there is the more modern version of the nuclear-communicative family where the parental couple has a positive relationship, which is a necessary condition in order to share the responsibilities involved in parenting. According to Katakis (1984) the factors that contribute 
towards this integral relationship include: a relationship which involves mutual caring, where communication channels are open, and where the marital relationship is more than taking care of the children (see pages 189-191 for a more detailed description). Katakis (1998) described the nuclear-communicative family as the more modern way of relating, although all three typologies exist simultaneously in the social terrain of the Greek family. Softas-Nall (2008) refers to Katakis' self-referential conceptual system model and describes this system of beliefs or constructions about family life that is constantly evolving. According to Softas-Nall (2008), the model can help researchers and family therapists identify, track and deal with the co-existing and at times conflicting constructions that people use to refer to their lives, the lives of significant others or social institutions in general.

The existence of multiple beliefs, values, roles, and constructions regarding family life, and more specifically motherhood, is also highlighted by Paxson (2004). Her anthropological research conducted in the 1990s focused on the paradoxical state of affairs regarding reproduction and motherhood in Greece. The question she posed was: why is it the case that a country with a deeply rooted value for bearing and having cohesive families has the lowest birth rates and the highest abortion rates in all of Europe? According to Paxson's (2004) analysis of in-depth interviews with Athenian women from varied age groups, being a woman and becoming a mother have traditionally been associated with sacrifice, a social imperative, and a lifetime of service to one's family, particularly to one's children. This service toward the common, social good or benefit and the nature of a woman's performance at this service is rewarded by social validation within the community.

After World War II and the Greek Civil War the ethic of choice became more prominent for women. However, dilemmas associated with trying to find the balance between the responsibilities and obligations of being a woman in a changing society and the rights to become a mother surfaced. This imposition is fraught with compromises, questions, and ethical speculations. Finally, 'modern women' perceive motherhood as a way to achieve personal stability, social balance and equanimity. Paxson (2004) details how all three of these 'ethics of reproduction' coexist and create the conflicted 'nootropia' or 'collective mentality' or societal 'normalizing pressures' (Paxson 2004, pp. 98-99) that permeates the social milieu of Greece. There is a collective mentality that places pressures on mothers to ensure that their children will become responsible cultural heirs and fulfill the destiny envisioned for them by their extended family and society.

Another decade and a half has passed since Paxson's research and the whirlwind of social change continues to be part of the Greek cultural milieu. From the present 
literature it can be seen that the iconic representation of the holy and goddess-like figure of the mother is well documented - however, more recent studies also highlight increasing personal and interpersonal frustrations and contradictions associated with the mothering role. Nevertheless, the over-riding impression that emerged from the literature was that Mediterranean mothers were often being 'pigeonholed' into certain broad based categories - and within the framework of these categories, the role of motherhood was frequently characterized as being fixed, stable and homogenous. Furthermore, the categories themselves - for example 'traditional' versus 'modern' may not in themselves always enable the researcher to make meaningful distinctions in a society experiencing social change. A major area of concern for us was that the most important voices, relating to Mediterranean motherhood - those of individual mothers themselves - are not currently being heard in the social science literature.

To summarize the literature review: The Doumanis study compares rural and urban landscapes, Dragona's (1987) focuses on new mothers and Katakis' (1998) book focuses on the entity of the family. Paxson's (2004) text, which reports 'individual voices' adopts an anthropological perspective and is primarily concerned with dilemmas women face when making decisions about whether or not to have children. In contrast to previous work, our research focuses solely on mothering in a specific context that is neither exclusively urban nor rural. This study explores the issue of motherhood as viewed by participants attending an open-ended community group conducted in Rethymnon, Crete, Greece.

The social context of the current study

Rethymnon, Crete, is a town of 31,700 people that has a long history dating back to the Minoan Era and is steeped in tradition. It is also a town that has experienced rapid growth and change over recent decades. Many of the current residents have moved to the city from neighbouring villages during the past 30 years, and the expansion of university departments and the development of mass tourism has also had a major impact on the structure and culture of the city.

In the 1980s the town of Rethymnon was the subject of work carried out by the anthropologist Michael Herzfeld (Herzfeld, 1991). He observed that some of the classic distinctions made by social scientists ceased to hold meaning when conducting research in this region. For example, as Herzfeld says: 'Gradually I stopped thinking about village and town as separate entities. Each is situated within the other's experience; each claims an identity that at once incorporates and 
rejects the self image of the other' (Herzfeld, 1991, p. 24). Herzfeld also asked the question about how one negotiates relationships with the past, present and future in a town such as Rethymnon. And whilst Rethymnon is a special place in which to live, we would argue that the town is by no means unique in this respect.

\section{Methodology}

Rationale for the study and target group

For the purposes of this research, the Lykeio Ellinidon in Rethymnon appeared to be the most suitable environment as an initial research base. It is a nonprofit organization that seeks to sustain Greek cultural traditions and also provides psychosocial support for families. The Lykeio runs a variety of community education programmes throughout the year. Our target group were women who had chosen to attend a nine week open-ended experiential group programme focusing on parenting issues (whilst the programme was open to all, the majority of attendees, over $90 \%$, were female). The group was diverse in nature in that the women were of disparate ages and social and educational backgrounds. However, the group may be considered to be relatively homogeneous in that it was made up of participants who were motivated to attend a parenting workshop. It seems plausible that those who attended the programme may have been more concerned about parenting issues than those who chose not to attend. Approximately $20 \%$ of the participants had attended parenting groups, 'sholes goneon' or 'schools for parents' but the programmes they attended had not focused on how they personally experience the parenting role. Moreover, the programmes that the participants had attended previously were educational and not experiential in nature. Data collection was conducted at the outset of the group, prior to the commencement of experiential activities and group discussions.

Aims of the study

To explore the lived experience of Cretan mothers from a reflective practice narrative perspective. We adopted a modified version of Murray's (2000) different levels of narrative analysis and a critical perspective. Murray (2000) outlined four levels of narrative analysis within health psychology: the personal, interpersonal, positional, and societal-ideological. Murray (2003) emphasizes that such a qualitative approach to the analysis of the lived experiences of people, allows the researcher to capture how people bring order to their stories and make sense of their ever-changing social milieu. Murray's approach has been previously applied to 
analyzing the narratives of older mothers in England by Shelton and Johnson (2006). The study sought to elucidate meanings and experiences of motherhood and mothering using narratives as vehicles in exploring their identities, interpersonal relations and socially shared stories, more specifically, :

- What are Cretan women's subjective experiences of motherhood and the parenting role?

- What is mothering for these women as they negotiate, attend to and balance their roles in relation to their own experiences of being mothered?

- What meanings do they ascribe to mothering?

- How do these narrative accounts link to wider social constructions of motherhood in Greece?

\section{Data collection methods}

A qualitative methodology was adopted, as this was considered appropriate to a study seeking to elucidate meanings and experiences of mothering. The study took the form of an open ended questionnaire format. Thirty-two participants provided written narrative accounts (in Greek) to six questions designed to tap into individuals' personal, interpersonal/intergenerational and societal perspectives on mothering experiences. The objective of the open-ended questions was to encourage participants to provide rich and full descriptions of their experiences of motherhood. Such descriptions would enable us to understand the participants' perspectives, subjective experiences and representations of mothering. This method was chosen in order to encourage the participants to narrate more crystallized and well thought-out accounts of their experiences of their mothering role and identity. Participants provided written informed consent. They were informed about the purpose and the nature of the study. The information provided emphasized that their written narrative accounts was an opportunity for them to tell their 'story' about what was important to them relating to their mothering experiences.

\section{Participants}

Forty-five sets of questionnaires were given out after one of the 'community group meetings' and thirty-two were returned via mail. The demographic characteristics of the women who completed the protocols were as follows: they ranged in age from 28 through 83 years, modal age range 41-50 years. 28 of the women were married, two were widowed and two were divorced. They varied in educational level with one woman having completed only primary school, one middle school, 12 women high school and 18 women some form of tertiary degree or professional training. All of the women had worked outside the home when they were raising their children. 
Six of the women had only one child, 19 women had two children, seven women had three children. Most participants were born and raised on Crete and two had lived in the area for the past 20 years. Table 1 presents a more detailed account the socio-demographic characteristics of the participants.

Table 1: Demographic characteristics of the participants

\begin{tabular}{|l|l|}
\hline$\underline{\text { Ages }}$ & 1 \\
$20-30$ & 7 \\
$31-40$ & 12 \\
$41-50$ & 8 \\
$51-60$ & 1 \\
$61-70$ & 2 \\
$71-80$ & 1 \\
$81-90$ & \\
\hline Marital Status & \\
\hline Married & 28 \\
Divorced & 2 \\
Widowed & 2 \\
\hline Education & \\
\hline Primary school & 1 \\
Middle School & 1 \\
High School & 12 \\
University & 15 \\
Technical and private training schools & 3 \\
\hline Number of children & 6 \\
\hline 1 & 79 \\
2 & \\
3 & \\
\hline
\end{tabular}

Research protocol and procedure

The questions (as translated into English) were as follows and were administered in the same order to all participants. The following questions were generated using previous international research on the intergenerational transmission of parenting (Chen \& Kaplan, 2001), the experience of motherhood Marshall (1991), the ideologies of mothering (Arendell, 2000), and Murray's levels of narrative analysis (2000):

- What does motherhood mean to you?

- What does society expect from parents? 
- What are the differences between a good and bad parent?

- It is said that nowadays we don't raise our children as we used to. What has changed? What has remained the same?

- Which of your parents' practices would you adopt or have you already adopted in the raising of your children? Which of them would you not adopt?

- What should parents pass down to their children?

Responses were given in Greek and were translated into English and then backtranslated to check for linguistic veracity. The analysis of the Cretan mothers' narratives was carried out in two phases, case and cross-case analyses, in which we employed both open and axial coding. In the case analysis phase each transcript was reviewed as a whole by the two researchers independently. Transcripts were initially subjected to thematic analysis using linguistic markers such as feelings, thoughts, attitudes/ perceptions, and actions. Responses were coded on an item-byitem basis, and subsequently according to individual protocols as a whole. In the cross case analysis, both researchers working together created meaning clusters based on the categories identified during the first phase and employed axial coding to assemble the data, pulling it together and examining commonalities, differences, and emerging patterns (Creswell, 1998). Table 2 presents the axial coding scheme.

Table 2: Themes and dimensions of mothering from the cross-case analysis and the axial coding phase

\begin{tabular}{|l|l|}
\hline Theme categories & $\begin{array}{l}\text { Dimensions of motherhood/mothering } \\
\text { Subjective meaning of } \\
\text { motherhood and mothering }\end{array}$ \\
\hline Identity, all encompassing, empowered socially \\
$>$ Role- caretaker, demanding, involving commitment and \\
diligence, hard work, great responsibility \\
$>$ Emotions- happiness, fulfillment, love, stress-anxiety, \\
ambivalence
\end{tabular}




\begin{tabular}{|c|c|}
\hline $\begin{array}{l}\text { Intergenerational transmission } \\
\text { of parenting practices }\end{array}$ & $\begin{array}{l}>\text { Similarities in how they their parents raised them and how } \\
\text { they are raising their children= love, transmission of core } \\
\text { social-cultural values and mores, education and } \\
\text { achievement as important accomplishment for children } \\
>\text { Differences= in the past parenting was characterized by } \\
\text { autocratic and authoritarian practices, a great deal of } \\
\text { pressure, strictness, pressure, and restrictions, adherence of } \\
\text { authoritarian ways by the educational system and social } \\
\text { systems in general } \\
>\text { Difficulties in reconciling what was intergenerationally } \\
\text { transmitted, do not want to be authoritarian, yet want } \\
\text { authority, do not want to adhere to strict and confining } \\
\text { practices yet fear for their children's well-being. }\end{array}$ \\
\hline $\begin{array}{l}\text { Societal expectations of } \\
\text { mothers }\end{array}$ & $\begin{array}{l}>\text { Proper upbringing of children } \\
>\text { Educate children both socially and with regard to } \\
\text { schooling (help children with school work, pay for tutors and } \\
\text { extra-curricular activities and lessons) } \\
>\text { Caring and upbringing should be 'proper' so that } \\
\text { children behave according to standards, are useful and } \\
\text { productive, and are ethical } \\
>\text { To be "totally present" for the upbringing of their children, } \\
\text { to give of themselves totally, to be incessantly committed to } \\
\text { their role, and 'without support' }\end{array}$ \\
\hline $\begin{array}{l}\text { Personal expectations of } \\
\text { mothers }\end{array}$ & $\begin{array}{l}>\text { "Good mother" = is interested, accepts her children as } \\
\text { they are, is giving, is selfless in the offering of love } \\
>\text { Bad mother = indifferent to children's needs, } \\
\text { overprotective, rejecting, is motivated by selfish motives, is } \\
\text { autocratic. }\end{array}$ \\
\hline
\end{tabular}

The axial coding system led to further analyses and the data were then assigned to three pre-defined categories, applying Murray's (2000) conceptual structure on the different levels of analysis of narratives: the personal, the interpersonal/ intergenerational, and societal/ ideological. Murray (2000) proposes that the positional level is a distinct dimension of analysis and describes this level as the relationship between researcher and participant. Being that the methodology was using written narrative accounts this was a level of analysis that was not considered. The personal level includes-affective, cognitive, identity components. This is the phenomenological level of analysis and it attempts to capture how the women organize their perceptions and feelings, and how they construct a sense of who they are as mothers. The interpersonal level of analysis considers the intergenerational/familial and other relational components of mothering. This level of analysis considers how participants describe interactions and interpersonal process shaped their identities. The ideological and societal levels of analysis were integrated 
in the women's narratives. Their stories reflected a dialectical and dialogical interplay between their narratives, their social world, and their positioning in that world. Greek societal ideologies, belief systems, discourses and representation, including the positioning of the subject in her social context, culture, or milieu, were articulated and analyzed at this integrated level. In the protocols provided by the participants, the social status and positioning of the women appeared to be an extension of their collective representations (societal- ideological) and was most obvious in the women's accounts of the 'demands' made by society in general or collective mentality (i.e. nootropia). Perhaps the nootropia encompasses the ideological and political positioning of the participants in ways that are difficult to disentangle but that perhaps address the position of the subject within the wider social-economic and political context.

The validity and credibility of the analyses were reviewed by peers (three Greek, female psychologists, mothers; two Greek female psychologists; and four male psychologists, all researchers within an academic department). The findings and interpretations of data were scrutinized as a way to establish credibility a method suggested by Lincoln and Guba (1985).

\section{Analysis and discussion}

Our analysis of the transcripts was based on aspects of the three levels of narrative analysis that Murray (2000) presents. The accounts provided by the participants would appear to fit quite neatly into three phenomenological dimensions: personal, interpersonal/transgenerational, and the ideological/societal levels.

Personal dimension

The participants' narratives of personal experience included feelings, thoughts, associations, and perceptions about mothering, and the meanings attributed to their experiences and the actions they take in every-day life.

As predicted by the nature of items employed in the open-ended questionnaire, the frames of reference used by the majority of participants employed a "psycho emotional" component elaborating on the emotional dynamics of mothering (Barlow, 2004). The women in our group described mothering using terms such as: "Everything", "the most important gift bestowed upon women" "Being a mother completes / fulfills a women", "Unceasing care and responsibility for everything which concerns children," "love (aghapi), compassion, support, wisdom," and 
"Becoming a complete entity / existence. This is the greatest gift I can offer myself, my parents and the society".

Motherhood for the women in our group was presented as an ultimate fulfilment of their destiny as women, socially and perhaps biologically inevitable. This coincides with anthropological research that highlighted how the social representations connected to femininity are completely interchangeable with those connected to motherhood (Du Boulay, 1986).

Within the group there was consensus (with all of the participants noting three to four of the following parental behaviors) about what constitutes core parenting norms. These included: demonstrating love and affection, being appropriate attachment models and educators, providing material support, imparting values such as respect, trust and honesty, and bringing up children to be independent individuals who were also 'decent' citizens. The decency values which emphasize character as described by the participants include: honesty, charity, patriotism, responsibility, religious piousness, respect to elders, loyalty to family and dignity. These values have also been emphasized in previous literature (Oh, 2010; Tamis-LeMonda, Wang, Koutsouvanou \& Albright, 2002). As one of our participants wrote:

It (mothering) stands for great responsibility but concomitantly a source of life. The role of the mother is accompanied with that of the pedadogue/ the nurse's role/ the friend's/ the adviser's and with a feeling that you no longer live just for yourself and you dedicate a great amount of your time to others. Through the mothering process, life has meaning, expectations, hopes and creativity (Twenty-seven year old, one child, university graduate).

Further illustrative examples include:

It is the most important role of my life. A role that will never change. I shall try to do my best. Because of this role, I feel important and significant (Forty-two year old, mother of two, high school graduate).

I am the mother of three children. My first priority is the care of my children, myself comes second. I do my best to be close to them, to foster their psychological and mental growth, and provide them with the material supplies that are essential to fulfill their needs. All of my thoughts, actions and practices aim at the improvement of my family functioning and the fostering of balance and the mutual respect of family members. (Forty-two year old, mother of 3, technical university graduate) 
Both of these participants describe the all-encompassing role of mothers and the importance of the role to them. Mothering is a priority for these women and their ability to perform well in the role is tied into their sense of significance.

[Motherhood is..] Becoming a whole entity. This is the greatest gift I can offer myself, my parents and society (Forty-three year old, mother of three, high school graduate).

[Motherhood] means constant giving, selfless love at all costs, proper role modelling. When the child grows up, [means] guidance without imposing oneself on the child, and being as discreet as possible. Responsibility, because children are the future. Even though we experience happiness and bliss, the constant care of the child doesn't allow us to take care of ourselves (Fifty-five year old, mother of three, university graduate).

[Motherhood is ...] The upbringing of individuals with character, full of love for their fellow citizens, with interests beyond themselves, intellectually developed, with knowledge and the abilities to contribute to the public welfare (Eightythree year old, mother of three, middle school education).

The three participants quoted above placed more emphasis the caring aspects of mothering. By caring and giving of themselves fully, they contribute to the social good and their status and identities are empowered. In order to contribute in this fashion however, they have to be vigilant and 'selfless'.

The women's responses suggest that their identities are shaped and formed by becoming mothers. Their accounts describe how this 'personal and social identity' achievement gives way to positioning them as primarily and ultimately responsible for their children's development. This positioning constitutes the women responsible for all that their children do and do not do, and hence they need to monitor, be constantly available, and provide mothering in an intense way so that they and their children pass the success 'stress tests' of social development. By and large, these norms corresponded to 'traditional mothering scripts' (Doucet, 2009; LeVine, 2010). In this case "scripts' of intensive mothering, where a mother is totally devoted to her children, is the sole source of guidance, nurturance, education, and physical and emotional sustenance for them (Johnston \& Swanson, 2007). This all-encompassing role corresponds to what Paxson (2004) described as the 'ethic of service', a way of mothering that is synonymous with devotion, self-sacrifice, and sole purpose. Service and devotion to their own parents and extended families, communities and religion is what society demands of these women. As Paxson (2004) found, within Greek 
society motherhood is an ontological relationship based on 'Christian aghapi' that is transformative, corresponds to a sense of selflessness, and completes a woman's identity. Oh's (2010) commentary highlights the religious underpinnings of this "sacrificial and selfless love" which tend to objectify women as "symbols of willing and selfless devotion" and create "simplistically idealized renderings of motherhood (pp938-639)." Through this ultimate fulfillment, women become responsible for the next generations moral future (Ruddick, 1989). As the mothers in our sample imply, mothering is a very essential and crucial role that synchronizes and synthesizes a woman's personal, social and ideological existence, as Paxson (2004) states: "When, as under the ethic of service, one's acts are motivated by external convention rather than inner imperative, everyone suffers thwarted yearnings, affections, and ambitions (pp.98-99)."

The gap between idealistic cultural expectations of mothering and the complexity of women's subjective experiences of mothering adds to women's dissatisfaction, ambivalence, and sense of demoralization that is highlighted in the international feminist literature (Quinn \& Luttrell, 2004; Tummula-Narra, 2009, LeVine, 2010; Oh, 2010; ). The pressure to be a 'good mother' was also emphasized in international literature. Feminists have highlighted that the dominant ideology of the 'good mother' positions women as natural caregivers, selflessly committed to their children and role as mothers (Nicolson, 1998, Forna, 1999, Choi, Henshaw, Baker \& Tree, 2005). They have argued that this is at odds with women's experiences of motherhood and it presents difficulties and conflicts for mothers, perhaps because it is experienced as a subtle form of oppression. The women of our study described their awareness of the societal pressures on women to be 'good' mothers, responsible not only for their own children, but for the nation's economical, moral, and overall survival.

In summary, the personal level of analysis underscores the all-encompassing nature of the mothering role, the selfless devotion it entails, and the never ending vigilance that it requires if they are to achieve the social status of a 'good mother' as it is dictated by familial and social pressures.

Interpersonal / transgenerational dimension

Women expressed the wish to be 'good' mothers as defined by familial expectations. However, these expectations were also seen as unrealistic 'ideals' at odds with the demands and pressures faced by Cretan mothers today. The women in our study found the construction of modern mothers' identities as fraught with competing pulls, allegiances, and anxiety provoking demands. More specifically, women felt compelled by both familial and intergenerational pressures to embrace 
expectations to be 'perfect' mothers. However, motherhood is also a crucial and significant identity achievement. In the past, mother's identities were more proscribed and there was little variance in role models, ideological discourses, and other societal pressures. For example:

Family members expect that parents' life should revolve around their children, and children to be the first priority of their parents (Fifty-year old, mother of one, bookeeping training).

Even relatives anticipate perfection from parent. (Forty-eight year old, mother of two, university graduate).

It means a great deal of responsibility, and no matter how hard I try to bring about the proper and desired result laccording to my experiences and the principles of my family of origin), it doesn't suffice, because the ways and mores according to which we were raised have radically changed. In other words, I realize that my effort isn't sufficient, and the result is not the expected one in many ways. That is surely upsetting. But when I see other children behaving somehow like my own, I am somehow relieved (Sixty-two year old, mother of two, university graduate).

The women describe the daunting expectations that come with the role of mother. They experience these intergenerationally transmitted demands as a great pressure and responsibility that they have internalized. The rapidly and constantly changing social context enhances the pressures involved in that what is 'expected' of mothers is very difficult to achieve in that they were raised and have incorporated ideals, values and mores that are difficult to apply and achieve in an ever evolving social context.

It is at this intergenerational/ familial level that participants voiced a great deal of dissonance and ambivalence. On the one hand, they wanted to adhere to their family's values and ways of being, on the other, they also cited the need to be less authoritarian, conservative, and strict and more communicative with their children than their own parents had been. Thus, participants wanted to instill the same values, but in a different way. The women are being asked to try and make a balance between being attentive and constantly giving mothers versus regulating and being persistently and consistently training mothers. There was a striking absence in the narratives of referents to the father's role. The women in this study appeared to experience their spouses as part of the family - intergenerational context that applied pressure to be a 'good mother' who adheres to the demands 
for vigilance and constant caring. It seems that the demands and cultural requirements of the role do not view mothers or wives as persons who may experience difficulties in coping with and adhering to these demands.

The ambivalence, guilt, and difficulties in reconciling 'perfect mothering' demands and highly idealistic expectations of 'intensive mothering' are well documented in the international literature (Arendell, 2000; Guendouzi, 2006; Shelton \& Johnson, 2006; Johnston \& Swanson, 2007; Wethington \& Kamp Dush, 2007). Shelton and Johnson (2006) attribute ambivalence and dissonance to the complicated nature of mothering experiences. These cumulative, life-long experiences are often contradictory emotionally. This paradoxical nature is described by one of the participants who said/felt/believed that mothering is 'everything' and but also involves "so many" contradictory things:

[Mothering is].... EVERYTHING. So many things: Endless love, completeness, my life is MEANINGFUL, has a FUTURE. My life is interesting. Yet, SADNESS, WORRIES and dead ends are present. My DISAPPOINTMENT is immense, I feel helpless, with my hands tied down, without being able to help (I feel PAIN, I feel LOVE). I cannot find the right words to describe what my children offer me. I could say, a priceless fortune, they support me, one joke of theirs can dissolve all the dark clouds that linger over my head. I cannot describe the devotion I feel for my children. Whenever I discuss with them, I am calmed down, I'm balanced. I think that these two children are my only achievement" (Forty-nine year old, mother of two, high school graduate) (emphasis in the original).

The words of the women in our study document how the powerful familial and intergenerational discourses of being a 'good' mother that raises 'proper' children inevitably enter women's understandings of themselves, and how the sense of being constantly evaluated by others regulates them. This emphasis is evident by the way the woman above structures her narrative, underlines important words and capitalizes the most emphatic meanings for her.

In summary, the intergenerational level of analysis taps into 'perfect mother' or good mothering demands that are derived from the close circle of family and community. These findings coincide with the myth of the 'perfect mother' that feminist scholars (e.g. Forna, 1999) have connected to the disparities between the ideologies of mothering and the lived experiences of women (Arendell, 2000). Since the mothering role is one that fulfills not only interpersonal and personal expectations but also societal roles, conflict and ambivalence was also obvious in the ideologicalsocietaldimensions of narrative analysis. 
Ideological and societal dimension

This level of analysis focuses on Greek society's 'collective mentality' 'nootropia' or common consciousness that is traceable to cultural history 'habitus' (see, for example, Paxson, 2004, p.99). Motherhood is a set of social relationships and these relationships go beyond the nuclear and extended family into the wider social and cultural context. This constantly shifting, constructed and reconstructed context of relationships kneads and forms mothering identities, subjectivities and ways of behaving and being (Paxson, 2004; Softas-Nall, 2008). In essence this socially embedded language, ways of being, and social representations pervade the lives of the participants and position them within their particular context. The women in our study linked the cultural and the subjective sense of who they are by voicing their uncertainty in negotiating the dialectic in being the 'perfect mother', and juggling more and more roles and handling an ever increasing number of socially circumscribed demands and regulations on what it means to have successful offspring. In a context which is currently in flux, economically, socially, demographically and even ecologically; the women in our study described how cultural narratives from different points in time co-exist and make their lives and efforts feel disjointed. Vosniadou (2009) captures the integration in these levels of analysis in her work on Greek women's identity by explaining describing how difficult "the passage from emancipation to autonomy, from certainty to uncertainty, from the politics of identity to a politics of conflicting and contradictory identifications, which the postmodern subject has to go through" (p. 40).

Today, life conditions have changed, yet research indicates that through the processes of enculturation and socialization (Seymor, 2010), the strong ideological scripts of mothering and motherhood are still deeply felt and enacted in daily familial interactions and broader societal discourses. On the one hand it is easier for the mother to take care of her children, because she has more commodities at her disposal, and much more help from experts. On the other, she has less available time and communal experiences of what mothering is all about. This creates more anxiety for mothers, because life rhythms are fast and parents are confused between the older authoritarian model and the modern more democratic model. They are stressed and concerned about their behaviour towards their children. This level of stress about the mothering role is something that possibly did not happen in the past, when the struggle for survival may have prevailed over everything else and when gendering practices were learned and enacted automatically and were taken for granted as deeply engrained collective practices. The 'intensive mothering' demands along with contextual encroachments, including a rapidly changing social context, economic pressures, decreased social cohesiveness and support impinge 
upon these women's subjectivities and identities, a conclusion that is echoed by researchers on mothering who are working in different contexts (Tummala-Narra, 2009).

In the words of the women of the study: "Society expects us to raise or teach our children moral and spiritual values. To educate children's souls so that they can enter society with dignity, self-respect, fighting spirit and become useful for the society" (Forty-three year old, mother of two, high school graduate).

Yet questions were also posed- "How does a woman go about doing this?" And,

I personally cannot tell who is the good and who is the bad parent, because if you are tolerant, you are considered mistaken. If you are strict, you are mistaken too. (Fifty-six year old, mother of two, university graduate).

The women write about their awareness of the societal pressures to be 'good' mothers that fuel their aspirations for vigilance and perfection and pose questions about these expectations with regard to their clarity and applicability in a changing context.

I am not really sure whether the good parent wants his children to be truly happy with what they are doing or he wants them to behave in a certain way so that they can appear nice and competent in the society (Forty-two year old, mother of two, high school graduate).

Society expects everything from the parents, whereas several messages should be conveyed by schools. Education falls SHORT (Thirty-eight year old, mother of two, middle School education).

Society expects every child to be useful, when she or he reaches maturity. Not to become a burden for the society, rather a whole and productive personality. Parents hold the greatest responsibility for the integration of their child's personality (Forty-nine year old, mother of one, high school graduate).

The women expereince the societal demands as daunting, they feel more and more accountable and responsible for their children's well-being and behaviour. Moreover, they feel unsupported and at loss as to how to go about reconciling the demands of the social context and the impact on their functioning and the psychological well-being of their children. 
Society expects us to give everything to our children, although it doesn't always support us. We certainly need support. Even though society trips us up, we do the best that we can without neglecting ourselves, because if we don't feel good about ourselves, we cannot perform our societal imposed duties as parents (Thirty-seven year old, mother of two, technical university graduate).

Society holds parents responsible for everything, for good or ill. School and society are accountable for very few things" (Fifty-seven year old, mother of two, university graduate).

Society expects that we should bring up perfect, flawless children (Fifty-six year old, moher of two, university graduate).

In a changing social context, the women expereince the demands for perfection in providing care and support and in raising 'perfect children' difficult to achieve. The economic and social restructuring adds to the demands and erodes the families' traditional social capital (Ambert, 1994).

....the decline of moral values, the constant questioning and controversy on what is right or wrong and the fact that children are influenced more by their friends and television and that their standards differ from ours, render our role really demanding. Our children question us all the time, they sometimes isolate us and our relationship becomes only financial, because they are dependent on us. When they stop being dependent, our point of view probably annoys them. Moreover, family structure has changed. Nowadays, there are single parent families (which is even harder). The grandmother and the grandfather are no longer respectable individuals, but have become nannies, and their opinion is not considered important. Parent's obligation to raise, to educate their children and support them financially until, they find a job land nowadays, it is hard to achieve this) remains the same (Fifty-five year old, mother of three, university graduate).

The societal constructs of mothering appear to position the mothers in our study against idealised images of how perfect mothers should be. The dialectical tensions and criticisms are evident between the ideologies of mothering and the experiences of these women. Yet, the dominant cultural discourses of the iconic status of mothers prevail making these women's experiences difficult to reconcile. The women describe how their roles as mothers correspond to the varied social representations that have existed in Greek society through the years. The focus on achieving these idealized representations of motherhood eclipses wider social explanations and 
processes that impact upon the formative experiences of children and families. Thus, great responsibilities are placed on parents (predominantly mothers) and the wider social context is not critiqued or in any way held responsible. As such, motherhood is simultaneously the ultimate fulfilment and empowering achievement, a role that is exhausting and demanding, a lifetime of service, a role without a definite script, regulated by societal demands, and a pivotal and constantly evolving aspect of who a woman is and what she wants to be. This is echoed in Katakis' (1998, see also Softas-Nall, 2008) work on family life and in Paxson's (2004) book on the ethics of reproduction in Greece. Concomitantly, in a rapidly changing social milieu the women noted that there was a lack of support from the wider social context, something that Doumanis (1983) had highlighted when referring to Athenian women. On the one hand, there is the ideal of the perfect mother who serves her children, her family, her society, and her nation diligently and competently in all spheres of existence without complaints. On the other hand there are the conflicts associated with demands of being a mother in the modern world.

\section{Conclusion}

From our study, it would appear that intrapersonal and interpersonal perceptions of Cretan motherhood are characterized by higher levels of dissonance and ambivalence than would have been predicted by the iconic representation of mothers as being saintly, highly valued and a perfect and universal role for women.

Mothers expressed considerable feelings of intrapersonal conflict associated with the need to reconcile the culturally ascribed role of mother within the context of a rapidly changing society. Traditional mothering scripts applied over generations were seen as no longer applicable. 'Updated' scripts did not appear to be available. It appears that modern cultural and social milieu of the women requires modern social relations and 'being holy figure' in this modern society weighs them down, confines them and impedes their sense of self-efficacy, individual initiative, and in personal worth. It is difficult for these women to establish other ways of gaining authority since both consciously and unconsciously they subscribe to the idea a people and a nation, Hellenism-nation, religion and family (Патріs,


bearing and proper rearing to embody, sustain and perpetuate these core values (Paxson, 2004; Vassiliou \& Vassiliou, 1970). The women appear to be stuck between the Scylla and the Charybdis, cultural and intergenerational values that bind and drastic changes that make women feel abandoned with the 'socializing' task and the search for a new more 'modern' personal identity. Hence, the over-riding view 
that emerged was that modern Cretan women were being expected to perform the role of mother without appropriate guidelines or support structures.

Vassiliou and Vassiliou (1970) describe this as children being "thrown into mother's sole responsibility" and "imprisoned within four walls in the mother-child relationship (prison of love?)" (p. 433). The mothers in our study are left feeling torn between demands for the old ways of being, their children's demands, their careers, and the pressures of the wider changing society. Their narratives of motherhood are heavily tied to and are confounded by the history of their culture and the new constantly evolving social world; hence their subjectivities are linked with uncertainty and they experience a disjointed sense of who they are. These findings coincide with some of the interdisciplinary international literature on mothering (Barlow, 2004; Doucet, 2009; LeVine, 2010; Oh, 2010; Quinn \& Luttrell, 2004; Ruddick, 1989; Seymor, 2010; TummalaNarra, 2009) on how the ecocultural and historical context shapes mothering, how contradictory feelings and tensions are part of the way women grapple with motherhood and how mothering needs to be understood in the context of multisystemic roles, positioning, and intergenerational relationships.

In this qualitative study motherhood was defined from the perspective of the women themselves based on the reality of their daily lives and their views of how the broader societal systems impact on their realities and subjective experiences in a rapidly shifting social context. Such methodology is important according to Amber (1994) and Arendell (2000) if motherhood is to be understood from women's own understandings and if research and practice is to become more cross-cultural and attuned to social change. To establish validity of the study the methodology, the findings, and the interpretations were reviewed by peers (in line with the methodological approach adopted by e.g., Lincoln \& Guba, 1985) on one occasion. A more thorough peer review would have strengthened the study further as would a replication using interviews or focus groups. Moreover, the findings presented here are descriptive in nature and clearly need further validation. However, it would appear that the research strategy that we have adopted - trying to tap into subjective representations of motherhood in a real world setting - has managed to generate 'different voices' from some Mediterranean mothers that may have been under-represented in the global scientific literature. This line of research can influence the work of practitioners. In order to have such an impact the role of fathers in the parenting process and also that of women who have not experienced motherhood or are about to become mothers needs to be studied and heard. 


\section{References}

Arendell, T. (2000). Conceiving and investigating motherhood: the decade's scholarship. Journal of marriage and family, 62(4), 1192-1207.

Ambert, A. M., (1994). An international perspective on parenting: social chance and social constructs. Journal of Marriage and Family, 56(3), 529-543.

Barlow, K. (2004). Critiquing the "good enough" mother: a perspective based on the Murik of Papua New Guinea. Ethos, 32(4), 514-537.

Chen, Z., Kaplan, H. B. (2001). Intergenerational transmission of constructive parenting. Journal of Marriage and Family, 63(1), 17-31.

Choi, P., Henshaw, C., Baker, S., \& Tree, J. (2005). Supermum, superwife, supereverything: performing femininity in the transition to motherhood. Journal of reproductive and infant psychology, 23, 167-180.

Cresswell, J. W. (1993). Qualitative inquiry and research design: Choosing among five traditions. Thousand Oaks, CA: Sage.

Doucet, A. (2009). Gender equality and gender differences: parenting, habitus, and embodiment (the 2008 Porter Lecture). Canadian Sociological Association, 46(2), 103121.

Doumanis, M. (1983). Mothering in Greece: from collectivism to individualism. London: Academic Press.

Dragonas, T. G. (1987). Greek women's attitudes toward pregnancy, labor, and infant: their significance for intervention. Infant mental health journal, 8(3), 266-276.

Du Boulay, J. (1986). Women- images of their nature and destiny in rural Greece. In J. Dubish (ed.). Gender and power in rural Greece, pp136-168. Princeton, NJ: Princeton University Press.

Forna, A. (1999). Mother of all myths: how society moulds and constrains mothers. London: Harper Collins Publishers.

Guendouzi, J. (2006). "The guilt thing": balancing domestic and professional roles. Journal of marriage and family, 68, 901-909. 
Herzfeld, M. (1991) A Place in History: Social and Monumental Time in a Cretan Town. Princeton, NJ: Princeton University Press.

Johnston, D. D., \& Swanson, D. H. (2007). Cognitive acrobatics in the construction of worker-mother identity. Sex roles, 57, 447-459.

Katakis, C. (1984). The three identities of the Greek family (I tris tautotites tis Hellinkis Ikoyenias). Athens: Kedros.

LeVine, R. A. (2010). Commentary: From the mother's point of view. Ethos, 38(4), 458460.

Lincoln, Y. S., \& Guba, E. G. (1985). Naturalistic inquiry. Thousand Oaks, CA: Sage.

Marshall, H. (1991). The social construction of motherhood: an analysis of childcare and parenting manuals. In A. Phoenix, A. Woollett, \& E. Loyd (Eds.), Motherhood: Meanings, practices and ideologies (pp. 66-85). London: Sage.

Murray, M. (2000). Levels of narrative analysis in health psychology. Journal of health psychology, 5, 337-347.

Murray, M. (2003). Narrative psychology. In J. A. Smith (Ed.), Qualitative psychology: a practical guide to research methods (pp111-131). London: Sage.

Nicolson, P. (1998). Post-natal depression: psychology, science, and the transition to motherhood. London: Routledge.

Oh, I. (2010). Motherhood in Christianity and Islam: critiques, realities, and possibilities. Journal of religious ethics, 38(4), 638-653.

Paxson, H. (2004). Making modern mothers: ethics and family planning in urban Greece. CA: University of California Press.

Quinn, N. \& Luttrell, W. (2004). Psychodynamic universals, cultural particulars in feminist anthropology: rethinking Hua gender beliefs. Ethos, 32(4), 493-513.

Ruddick, S. (1989). Maternal thinking: toward a politics of peace. Boston: Beacon.

Shelton, N., \& Johnson, S. (2006). "I think motherhood for me was a bit like a doubleedged sword': the narratives of older mothers. Journal of community and applied social psychology, 16, 316-330. 
Softas-Nall, L. (2008). A view of systemic therapy in Greece: an interview with Charis Katakis. The family journal, 16, 87-91.

Seymour, S. (2010). Commentary: Who, how, what, and why? Ethos, 38(4), 449-457.

Tamis-LeMonda, C. S. Wang, S. Koutsouvanou, E., \& Albright, M. (2002). Childrearing values in Greece, Taiwan, and the United States. Parenting: science and practice, 2(3), 185-2008.

Tummala-Narra, P. (2009). Contemporary impingements on mothering. American journal of psychoanalysis, 69(1), 4-21.

Vassiliou, G. (1966) An investigation of the psychodynamics of the Greek family Athenian Institute of Anthropos - Technical Report No. 5. (in Greek)

Vassiliou, G. \& Vassiliou, V. (1970). On aspects of child rearing in Greece. In E. J. Anthony and C. Koupernik, (Eds.), The child and his family (pp. 429-444).. New York: Wiley.

Vosniadou, T. (2009). From demanding emancipation to negotiating autonomy: conflicting identifications in a changing world. Psychotherapy and politics international, $7(1), 40-47$.

Wethington, E., \& Kamp Dush, C. M. (2007). Assessment of parenting quality and experiences across the life course. Interpersonal relations across the life course advances in life course research, 12, 123-152.

About the authors:

Sofia Triliva, Assistant Professor, Department of Psychology, University of Crete, University Campus at Gallos, Rethymnon, Crete 74-100 Greece.

Email: triliva@psy.soc.voc.gr

Catherine M. Brusten, PhD. Patriarchou Grigoriou 11, Rethymnon, 74-100 Crete, Greece. 